\title{
AMNÉSIA TRANSITÓRIA SELETIVA
}

\author{
NUNJo FinkeL *
}

Esta comunicação tem como finalidade divulgar uma condição por nós recentemente observada e aparentemente não descrita, de maneira específica, na literatura especializada. Deliberamos cunhar, provisòriamente, a denominação de amnésia transitória seletiva para preços de mercadorias (ATSPM) como rótulo sindrômico para a condição que nos propomos a delinear, em analogia com a síndrome de amnésia global transitória consignada por Miller Fisher e Adams ${ }^{6}$ em 1964. A denominação por nós alvitrada, embora longa, tem o mérito de ser auto-definida, traduzindo essencialmente uma incapacidade seletiva em evocar preços de mercadorias, num período geralmente de algumas horas, por parte de comerciantes experimentados.

\section{OBSERVAC̄OES}

CASO 1 - W. D., com 72 anos de idade, branco, natural da Rússia e procedente de São José dos Campos, casado, comerciante. H.D.A. (colhida em 10 de julho de 1966, sendo informantes o paciente e seus familiares) - No dia 3 de julho de 1966 o paciente acordou com cefaléia tolerável, fato êste que ocorre desde os 15 anos de idade à razão de 2 a 3 vêzes por semana, tendo feito uso de analgésico à base de ácido acetil-salicílico com cessação pronta da dor. No dia seguinte dirigiu-se, como de hábito, à sua loja comercial às 7,30 horas e às 8,15 horas atendeu o primeiro freguês. Nesta ocasião observou incapacidade em informar o preço da mercadoria desejada, solicitando auxilio do balconista. Tal situação repetiu-se seguidamente quando interpelado pelos freguêses que se sucederam. Retirou-se para os fundos da loja, alertando o balconista que "não estava bem" e que o substituisse. Ato contínuo, teve uma percepção mais aguda da sua incapacidade ao auto-perguntar o preço de tal ou qual artigo de sua loja e, logo a seguir, o número do telefone do filho e da filha, do ano presente, obtendo em resposta números que julgava incorretos ou bloqueio ideativo completo. Sobreveio ansiedade em relação ao seu estado e a noção de que "se perder a memória nāo presto mais para nada". As 11,30 horas voltou ao lar, nas proximidades da sua loja, para almoçar, comentando a ocorrência com sua espôsa, a qual nada observou de anormal na conduta, linguagem ou fisionomia do paciente. Em seguida ao almôço, repousou por meia hora, tendo retornado à loja. A partir das 13 horas, começou a processar-se recuperação gradual da memória para números e, ao fim da tarde, julgava-se completamente recuperado, restando fadiga nos membros inferiores, que relacionava com a manutenção prolongada na posição de pé exigida

* Da Clínica Neurológica do Hospital dos Servidores do Estado, Rio de Janeiro, GB. 
para o desempenho das suas atividades comerciais. Nega episódios prévios, turvaçōes de consciência, trauma craniano recente ou fenômenos outros dignos de nota. Exame neurológico - Marcha e estática normais. Tensão arterial $150 \times 80 \mathrm{~mm} \mathrm{Hg}$. Fundos oculares: papilas com limites nitidos. Campo visual por estimulação dupla e simultânea normal. Motilidade ocular extrínseca intacta. Não há nistagmo. Face simétrica. Demais nervos cranianos sem alteraçōes. Fôrça muscular, tono e coordenação normais. Sensibilidade intacta a tôdas as modalidades. Psiquismo e linguagem integros. Reflexos musculares simétricos. Reflexos plantares em flexão. Dominância: hemisfério esquerdo. O exame físico geral nada revelou de significativo, assim como os exames complementares (glicemia, azotemia, hemograma, exame de urina, radiografias de tórax e crânio, eletrencefalograma e eletrocardiograma).

Caso 2 - H. S., com 61 anos de idade, branco, natural da Rússia e procedente do Rio de Janeiro, casado, comerciante. H.D.A. (colhida em 15 de setembro de 1967, sendo informantes o paciente e seus familiares) - o paciente julga-se homem de memória previlegiada. No dia 14 de setembro de 1967, em seguida à refeição matinal, por volta de 7,30 horas, dirigiu-se ao seu estabelecimento comercial. As 8,30 horas, abriu as portas de sua loja, iniciando as suas atividades conferindo faturas. As 8,45 horas, ao tentar evocar o preço de determinado tecido, viu-se incapaz de fazê-lo com exatidão, ocorrendo-lhe várias cifras que percebia serem logo incorretas. Logo a seguir tentou evocar os preços dos demais artigos expostos na loja que não tinham cartazes afixados com os valores. Observou então incapacidade em evocar qualquer cifra ou, então, evocava preços que percebia não corresponderem a realidade, sendo, entretanto, perfeitamente capaz de ler os preços de alguns dos artigos anunciados em cartazes. A instalação de tal quadro preocupou-o de imediato, contendo-se, no entanto, para nāo denunciar sua ansiedade aos demais funcionários do estabelecimento. Sobrevieram fantasias malignas relativas à perpetuação da amnésia limitada a preços, tendo então solicitado de um dos balconistas que anotasse os preços de tôdas as mercadorias em papel a parte. Em seguida, tentou telefonar para a sua espôsa, não lhe ocorrendo porém o número da sua residência, sendo obrigado a consultar o catálogo de telefones. Em colóquio com sua espôsa, informou-a do que estava sucedendo, solicitando que a mesma comparecesse à loja mais cêdo que de hábito. Findo o telefonema, sentou-se e começou a ler o jornal da manhā, limitando-se à leitura de telegramas internacionais (que reproduz com perfeição por ocasião dêste exame), evitando a leitura de artigos mais densos ou editoriais com receio de que um esfôrço intelectual maior pudesse prejudicá-lo. Estando sentado e circunvagando os olhos pelas mercadorias expostas lia prontamente os preços afixados, mas qualquer tentativa de evocar preços das demais mercadorias sem os cartazes informativos gerava bloqueio ou a lembrança de cifras que não the pareciam corretas, razão pela qual evitava o atendimento de freguêses. Tinha a sensação que alguém passara uma esponja exclusivamente sôbre os preços das mercadorias que tinha de memória. Precisamente às 10,45 horas (2 horas após o início da amnésia), de modo gradual, começaram a ocorrer com exatidão os preços dos artigos da sua loja e, alguns minutos após, para sua perplexidade, lembrava-se perfeitamente de todos os precos. Nega formalmente episódios similares anteriores, preocupações de ordem comercial ou financeira ou trauma craniano recente. Exame neurológico - Marcha e estática normais. Tensão arterial $150 \times 100 \mathrm{~mm} \mathrm{Hg}$. Fundos oculares: papilas com limites nitidos. Campo visual, por estimulaçōes dupla e simultânea, normal. Motilidade ocular extrínseca intacta. Não há nistagmo. Face simétrica. Demais nervos cranianos sem alteraçôes. Fôrça muscular, tono e coordenação normais. Sensibilidade intacta a tôdas as modalidades. Psiquismo e linguagem integros. Reflexos musculares simétricos. Reflexos plantares em flexão. O exame fisico geral nada demonstrou de significativo. Dominância: hemisfério esquerdo. 


\section{COMENTARIOS}

Nossos dois pacientes, ao propiciarem suas respectivas histórias, recordavam-se com rigor de todos os eventos e circunstâncias ocorridos por ocasião dos episódios de ATSPM, assim como analisavam criticamente as suas reações emocionais e processos ideativos associados ao periodo amnésico seletivo.

Amnésia significa literalmente perda de memória e, clìnicamente, exterioriza-se pela informação do paciente ao dizer-se incapaz de evocar um determinado evento, pessoa, local ou período de tempo ${ }^{12}$. Amnésia dita organogênica pode ser prontamente separada da psicogênica, conforme está inserido nos livros de texto. Amnésia psicogênica tem sido visualizada como produto de repressão de material altamente traumático sob o ponto de vista emocional e de perda de identidade, enquanto amnésia organogênica não teria relação alguma com conflitos ou problemas pessoais. Recentemente esta dicotomia tem sido desafiada. Assim, foi demonstrado que, seguindo-se a tratamento por eletrochoque ou outras modalidades de injúria cerebral, a amnésia que se processa pode assumir características seletivas relacionando-se a áreas conflitivas do paciente e destacando-se sob um fundo de amnésia generalizada de caráter transitório. Assinale-se que os nossos dois pacientes, por serem comerciantes, no seu processo de relacionamento com o mundo, têm nos preços uma linguagem de extrema importância. Assim é que poderia nos ser dado conjecturar que, independentemente de uma gênese orgânica para a ATSPM, a expressão amnéstica seletiva poderia ser um subproduto de imposição profissional, porquanto preços e cifras em geral predominam como símbolos de alto significado nos processos de comunicação verbal dos comerciantes.

Sob questionário direto, não se constatava amnésia ou lacunas importantes relacionados aos dias ou horas precedendo o inicio da ATSPM e, findo o episódio, os nossos pacientes voltaram às suas atividades com desempenho de rotina. Os dois pacientes negavam taxativamente problemas de ordem comercial, financeira ou afetiva e, à entrevista psiquiátrica, não se detectavam mecanismos neuróticos ou psicóticos. Dest'arte ,o estabelecimento de uma relação de causa e efeito que conduzisse a uma gênese puramente psicogênica para a síndrome em apreço tornou-se problemática. História de trauma crânio-encefálico, recente ou passado, não foi obtida.

O comportamento dos pacientes no curso dos episódios, consoante as testemunhas, nada evidenciou de significativo ou contributório para uma elaboração etiológica. Não se observaram abalos musculares, alteraçōes de nivel de consciência ou de linguagem, enunciação de queixas outras senão aquelas concernentes à impossibilidade de evocação de preço dos artigos à venda, ou verbalização de material de caráter alucinatório, delusional ou delirante. Surtos com caracteristicas similares no passado foram sumàriamente negados por pacientes e familiares. A experiência amnéstica seletiva dos nossos pacientes era veiculada ao examinador de modo apropriado e completo, inclusive com fornecimento da hora de início e fim (confirmado por testemunhas); ambos as pacientes externaram a sua perocupação pela ocorrência da ATSPM e temiam a sua eventual recidiva. 
Idênticamente aos casos de "Transient global amnesia" relatados por Miller Fisher e Adams ${ }^{6}$ em 1964, os dois pacientes motivo dêste registro eram idosos (72 e 61 anos de idade, respectivamente). Nos dois casos, a condição ocorreu nos locais de trabalho de sua propriedade e no curso de atividades que lhes eram inerentes e familiares de longa data, sem quaisquer sinais prodrômicos. Por ocasião dos episódios, sempre pela manhã, houve preservação da crítica, comprovada, inclusive, pela tomada de providências pragmáticas, objetivando neutralizar a falha seletiva na evocação de cifras comerciais. Questionário específico e exaustivo proposto aos pacientes e familiares (o do caso 1 era pai de médico e o do caso 2 era sogro de médico), pertinente a sintomas e sinais indicativos de epilepsia temporal e, mais precisamente, de afasia epiléptica incidindo simultâneamente com a ATSPM, resultou totalmente negativo. Cumpre assinalar que a amnésia dos nossos pacientes, se bem que virtualmente limitada a preços de mercadorias, transbordou para outros números (telefone, ano do nascimento de filhos).

No que tange à etiologia dos episódios em tela, a inexpressividade da nossa casuística e da investigação de rotina e a falta de outras coordenadas, tornaria meramente especulativa qualquer consideração maior. A idade dos pacientes e a rapidez relativa dos acessos seria compatível, à guisa de hipótese de trabalho, com uma expressão inusitada de insuficiência cérebro-vascular intermitente por transtôrno hemodinâmico. Assim sendo, a alteração isquêmica se localizaria, conforme os conceitos atuais de anatomia de memória, na circunvolução do hipocampo (ou em suas conexões com o sistema límbico e diencéfalo) nos corpos mamilares, na substância cinzenta peri-aquedutal do tronco cerebral e tálamo ou na região têmporo-parietooccipital do hemisfério dominante. No entanto, seria temerária a exclusão pura e simples de um fenômeno epiléptico de caráter inibidor de natureza indeterminada ou mesmo o afastamento de uma etiologia metabólica transitória (e.g. hipoglicemia).

A idade, a configuração da personalidade dos pacientes, a sua trajetória de vida e a composição dos episódios, certamente não favorecem uma causa psicogênica de tipo histérico ou simulação com objetivo de ganho secundário.

A brevidade dêste registro nos libera de uma revisão atualizada dos mecanismos de memória e de seus distúrbios e das amnésias em geral.

\section{RESUMO}

O autor descreve uma síndrome clínica aparentemente não consignada na literatura especializada, expressa por amnésia transitória seletiva para preços de mercadorias. São apresentados dois casos, ambos referentes a comerciantes idosos, ilustrativos da condição para a qual o autor propõe a designação de amnésia transitória seletiva para preços de mercadorias (ATSPM), em analogia com a síndrome de amnésia global transitória consignada por Miller Fisher e Adams em 1964. 


\section{SUMMARY \\ Transient selective amnesia}

The author describes a clinical syndrome apparently not documented in the specialized litterature and expressing itself by a transitory and selective amnesia limited to merchandise prices. Two rather illustrative cases both in elderly dealers are reported. The author proposes the designation of transiente selective amnesia for merchandise prices (TSAMP) for the syndrome herein described in analogy with the syndrome of transient global amnesia reported in 1964 by Miller Fisher and Adams.

\section{REFERENCIAS}

1. FINKEL, N. - Negação de doença e outros distúrbios psíquicos associados a disfunção cerebral. J. bras. Psiquiat. 7:12, 1958.

2. JANIS, I. L. - Psychologic effects of electric convulsive treatments: post treatment amnesias. J. Nerv. Ment. Dis. 111:359, 1950.

3. KRAL, V. A. - The amnestic syndrome. Mschr. Psychiat. Neurol. 132:65, 1956.

4. KRAL, V. A. - Amnesia and the amnestic syndrome. Canad. Psychiat. Assoc. J. $4: 61,1959$.

5. MACKAY, R. P. - Memory as a biological function. Amer. J. Psychiat. 109: $721,1953$.

6. MILleR FISHER, C. \& ADAMS, R. D. - Transient global amnesia. Acta neurol. scand. supl. 9, 1964.

7. PENFIELD, W. \& MILNER, B. - Memory defect produced by bilateral lesions in the hippocampal zone. A. M. A. Arch. Neurol. Psychiat. 79:475, 1958.

8. RAPAPORT, D. - Emotions and Memory. International Universities Press Inc., New York, 1950.

9. RUSSEL, W. R. - Brain, Memory, Learning. Clarendon Press, Oxford, 1959.

10. SYMONDS, C. - Disorders of memory. Brain 89:625, 1966.

11. WEINSTEIN, E. A. \& KAHN, R. L. - Denial of Illness: Symbolic and Physiological Aspects. Charles C. Thomas, Springfield (Illinois), 1955.

12. WeINSTEIN, E. A.; MARVIN, S. L. \& KELlER, N. J. A. - Amnesia as a language pattern. Arch. Gen. Psychiat. 6:259, 1962.

Avenida Princesa Isabel 150, sala 704 - Rio de Janeiro, GB - Brasil. 